
doi:10.1017/ipm.2018.25

\title{
A survey of mental disorder in the long-term, rough sleeping, homeless population of inner Dublin - Corrigendum
}

\section{F. Hynes, K. Kilbride and J. Fenton}

https://doi.org/10.1017/ipm.2018.23. Published by Cambridge University Press, 28 May 2018.

Key words: Homeless, mental disorder, mental illness, psychiatric illness, rough sleeping.

In the original publication of this article, Fig. 1 had an error in the 'SMI only' circle which should read as 3 instead of 2. Please see the corrected figure below:

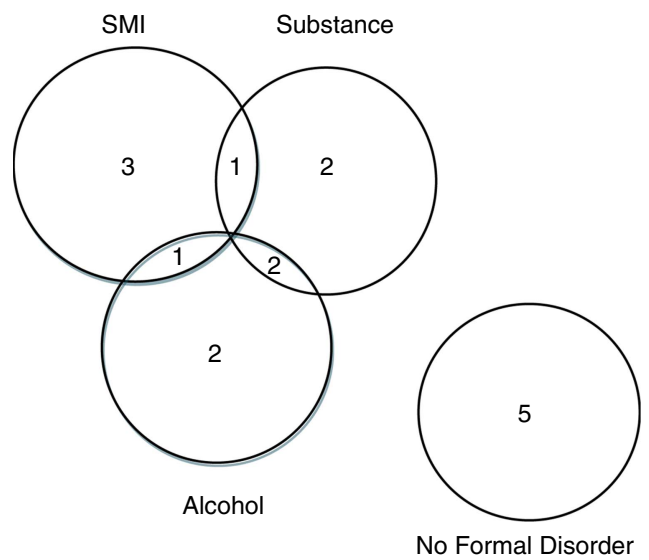

Fig. 1. Diagnoses.

SMI; severe mental illness. Alcohol; Alcohol related disorder. Substance; substance related disorder.

\section{Reference}

Hynes F, Kilbride K, Fenton J (2018). A survey of mental disorder in the long-term, rough sleeping, homeless population of inner Dublin. Irish Journal of Psychological Medicine, 1-4. https://doi.org/10.1017/ipm.2018.23. 